\title{
THE INFLUENCE OF AGGRESSIVE DRIVING BEHAVIOR AND IMPULSIVENESS ON TRAFFIC ACCIDENTS
}

\author{
Milanko Čabarkapa ${ }^{1}$, Marjana Čubranić-Dobrodolac ${ }^{2}$, Svetlana Čičević ${ }^{3}$, Boris Antić ${ }^{4}$ \\ ${ }^{1}$ University of Belgrade, Faculty of Philosophy, Belgrade, Serbia \\ 2, 3,4 University of Belgrade, Faculty of Transport and Traffic Engineering, Belgrade, Serbia
}

Received 25 March 2018; accepted 9 June 2018

\begin{abstract}
Findings from numerous studies pointed out the importance of studying certain forms of behavior and personality traits in order to understand propensity to commit unsafe maneuvers in traffic. The present study aims at evaluating the potential contribution of impulsiveness and aggressive driving in the prediction of traffic accidents, and at investigating relationship among them. Besides, the second main goal is to compare the levels of impulsiveness and aggressiveness among three considered groups: bus drivers, truck drivers and non-professional drivers. Participants were 305 drivers who completed the BIS-11 (Barrat Impulsiveness Scale) and ADBQ (Aggressive Driving Behavior Questionnaire). Research sample comprised of 202 professional drivers (bus drivers and truck drivers), and 103 non-professional drivers. The results showed a statistically significant relationship between impulsiveness correlates and correlates of aggressive driving behavior. Bus drivers and truck drivers showed higher levels of impulsiveness in comparison to non-professional drivers, while the highest level of aggression is recorded among non-professional drivers, followed by truck drivers and bus drivers. Finally, the results of hierarchical regression analysis showed that impulsiveness as a personality trait, as well as aggressive driving, are good predictors of traffic accidents.
\end{abstract}

Keywords: Aggressive driving, impulsiveness, traffic accidents, bus drivers, truck drivers, non-professional drivers.

\section{Introduction}

Injury and deaths due to road traffic accidents have emerged as an important public health issue which needs to be tackled by state institutions, researchers and society in general. According to the World Health Organization (WHO, 2014), about 1.25 million people die each year as a result of road traffic crashes. Studies show that a human factor is responsible for around $90-95 \%$ of traffic accidents (Evans, 1991). To improve traffic safety, it is obvious that a human behavior which increase the odds of being involved in a crash should be determined and further investigated with the aim to be prevented. Very important question in the considered field is related to the possibility of accurate prediction and forecasting a risky driving behavior mediated by driver's personality traits, which should be based on a multi-factor framework. An extensive body of literature has been devoted to explore and analyze the impact of personality traits on the occurrence of traffic accident (for example: Elander et al., 1993; Furnham and Saipe 1993; Ulleberg and Rundmo, 2003; Clarke et al., 2006; Koushki et al., 2006;

${ }^{2}$ Corresponding author: marjana@sf.bg.ac.rs 
Waylen and McKenna, 2008; Kanaan et al., 2009; Eiksund, 2009; Scott-Parker et al., 2009; de Oña et al., 2013; Sârbescu et al., 2014). There are studies which documents the personality traits are not proven to be a direct predictor of crashes (Furnham and Saipe, 1993; Ulleberg and Rundmo, 2003); however, through certain forms of driving behavior, it is possible to predict one's level of risk toward experiencing a road accident (Elander et al., 1993).

\subsection{Impulsiveness}

Although there are different definitions of impulsiveness in the literature, in the broadest sense impulsiveness is defined as a tendency to react quickly and unexpectedly, without thinking about the negative consequences of such a response or alternative reactions (Plutchik and van Praag, 1995, Moeller et al., 2001). The ambiguity that surrounds the construct of impulsivity has largely arisen from disagreement concerning the processes that cause this rapid, spontaneous, excessive, and unplanned behavior. While other similar constructs, particularly aggression, captures a similar set of behavioral characteristics, and overlap of theoretical concepts to a certain extent, it is hard to differentiate them. Based on this theory, (Critchfield et al., 2004) justify the use of the term impulsive aggression, initially suggested by Baratt and Slaughter (Barratt and Slaughter, 1998) as a single trait-like dimension. Despite the apparent conceptual overlap and close relationship between these two phenomena, in terms of poor appraisal of behavioral outcomes during decision-making, as well as insufficient selfcontrol, they should not be equated, whereas aggressive behavior as opposed to impulsive, includes the intent to harm the other person.
Individuals who often display such behavioral tendencies in daily activities are assumed most likely to react in similar manner on the road. Impulsive driving involves a tendency to immediately satisfy drivers' needs and to neglect the needs of other road users, as well as overall traffic safety. Given that impulsivity implies a predisposition toward rapid, unplanned reactions to internal or external stimuli, it could lead to unsafe behaviors such as: not wearing seat belts, driving under the influence of alcohol, ignoring traffic signs and signals, risky and aggressive driving styles, as well as increased accidents proneness (Hansen, 1988; Stanford et al., 1996; Dahlen et al., 2005; Renner and Anderle, 2000; Jakubczyk et al., 2013). Aggressiveness, impulsivity and another similar personality treats such as sensation seeking seem to be the most important behavioral factors in traffic (Jonah et al., 2001; Dahlen et al., 2005). Based on a survey with 797 drivers, (Hatfield et al., 2014) examined how sensation seeking impacts a relationship between perceived risk and risky driving. The results suggest that the Thrill and Adventure Seeking (TAS) subscale of Zuckerman's (1994) Sensation Seeking Scale moderate the relationship of perceived risk with risky driving.

Many instruments have been designed to measure impulsiveness, which is, in the literature often associated with various manifestations of risky behavior or experienced traffic accidents. The most frequently used and best established of these are questionnaires Barratt Impulsiveness Scale - 11 (Patton et al., 1995), Urgency, Premeditation, Perseverance, and SensationSeeking (UPPS) Impulsive Behavior Scale (Cyders et al., 2007) and Eysenck Impulsivity Scale (I7) (Eysenck and Eysenck, 1978). 


\subsection{Aggressive Driving}

Driving theories suggest that aggression originates from an externally elicited drive or motive to harm others (Harre and Lamb, 1983). Aggression is any form of behavior directed toward the goal of harming or injuring another living who is motivated to avoid such treatment (Baron and Richardson, 1994, Anderson and Bushman, 2002). Reports of aggression in the context of driving cite different forms of behavior in traffic that range from flashing lights, honking, verbal threats to other traffic participants, gestures, incapacity to maintain the proper distances from other vehicles, blocking and cutting the road to other vehicles up to more pronounced forms of aggressive behavior, such as car ramming or even physical attacks on other drivers (Özkan et al., 2010). In attempts to define aggressive driving behavior the definition given by Tasca (2000) deserves attention to be mentioned: "A driving behavior is aggressive if it is deliberate, likely to increase the risk of a collision, and is motivated by impatience, annoyance, hostility, and/or an attempt to save time". In the report of AAA Foundation for Traffic Safety, aggressive driving behavior has been identified as the basic cause of $56 \%$ of accidents with fatalities occurred in America between 2003 and 2007 (AAA Foundation for Traffic Safety, 2009). For better understanding of aggressive driving, it is important to emphasize that characteristics such as values, beliefs, attitudes, and intentions (Parker et al., 1998, Fernandes et al., 2007, Ge et al., 2016), demographic characteristics (Krahé and Fenske, 2002; Miles and Johnson, 2003) and personality traits (Deffenbacher et al., 2003; Dahlen et al., 2005; Bone and Mowen, 2006; Benfield et al., 2007; Jovanovic et al., 2011; Dahlen et al., 2012) contribute significantly to the explanation of this construct. Among the most frequently mentioned demographic variables that have a direct impact on the manifestation of aggressive driving, commonly referred are gender, age and driving experience (Tasca, 2000). While there is an agreement among different authors about the influence of age and driving experience on the expression of aggressive driving, it is not the case when it comes to gender as a predictor of aggressive driving.

It is often difficult to maintain sharp distinctions among anger and aggression as personality constructs. Anger is emotion which cause many forms of aggression behavior. Therefore, behind aggressiveness there is usually anger as a subjective experience. Thus, some studies indicate that anger is a robust predictor of aggressive driving (Deffenbacher et al., 1994, 2002). Deffenbacher and colleagues have identified differences in driving based on different personality traits of drivers. They have shown that individuals with elevated level of anger, anxiety and impulsiveness are more prone to aggressive and risky driving behavior and experience more accidents accordingly. However, there are authors that emphasize the limited predictive effects of these characteristic, because of its transparency to respondents and susceptibility to distortion response (Dahlen et al., 2012). In the theories which analyzed the behavior of drivers, it was postulated that aggressive driving is associated with the risky behavior and emotional states, all of which consequently leads to the impairment of relevant driving performance, such as reasoning, attention, perception, information processing, and psychomotor coordination (Arthur et al., 2005; Deffenbacher et al., 1994) with the final outcome of enhanced accidents prediction. 
Regarding the association between aggressiveness and negative outcomes in driving, such as traffic accidents, there are several recent studies which confirmed this relationship. The most frequently used instruments for aggressiveness assessment on road are the Driving Anger Scale - DAS (Deffenbacher et al., 1994), Driving Anger Expression Inventory - DAX (Deffenbacher et al., 2002) and Aggression Questionnaire - AQ(Buss and Perry, 1992).

The present study attempts to explain the predictive power of impulsiveness as personality trait and aggression expressed through behavior in traffic, as well as how the drivers' demographics shape predisposition for traffic accidents. Also, the aim is to provide empirical evidence of the relationship between the impulsivity and aggressiveness constructs when considered as traits. Finally, impulsiveness and aggressiveness levels were compared for three considered groups: bus drivers, truck drivers and non-professional drivers.

\section{Method}

The following sections provide detailed descriptions of the sample, methodologies for data collection, measures and statistical analysis.

\subsection{Sample}

Results presented in this paper are the part of a comprehensive research carried out on the road called Ibarska magistrala, i.e. the road of IB order 22 which is officially one of the busiest roads with the highest number of dangerous driving spots in the Republic of Serbia. Dangerous driving spot in the professional literature is often referred to as a black spot. In the Republic of Serbia, it is defined in the following way: A black spot is a road section maximum 300 meters in length, where occurred at least 10 traffic accidents, with at least 2 deaths and 4 injured persons over a period of 3 years (Road Traffic Safety Agency, 2015). Therefore, the respondents in the current study were drivers who regularly use the above road section. However, the proposed methodology is generally applicable and could be used for any other group of drivers.

The sample is composed of 305 drivers who voluntarily completed the questionnaires. The sample includes 202 professional drivers (100 intercity bus drivers and 102 truck drivers) and 103 amateur drivers. In determining the sample size, the authors took into account the Annual Average Daily Traffic on the observed road section (Roads of Serbia, 2016). As far as gender distribution concerned, the sample consisted of 268 males ( $88 \%$ ) and 38 female drivers (12\%). Among professional drivers there were no female subjects. Considering the age structure, subjects' age ranges from 36 to 45 years $(46.2 \%)$, while the average annual mileage traveled in the sample is in the range of 50,000 to $100,000 \mathrm{~km}(40.8 \%)$. Regarding driving experience, the majority of drivers have received a valid driving license from $16-25$ th year (35.7\%).

At the beginning of the study, detailed instructions were presented and explained to subjects. They were asked to fill out (carefully and honestly) the questionnaires, and no to linger too much thinking about certain issues. Also, it was emphasized to the participants that the testing is voluntary and anonymous, that all the data and information will be kept confidential and that results will be used only for the scientific purposes. In this way, it was further clarified 
to the professional drivers that the research outcomes will have no impact in any way on their occupational status.

\subsection{Measures}

Three questionnaires were employed in the study: extensive demographic questionnaire, the Barratt Impulsiveness Scale (BIS-11, Patton et al., 1995) for measuring selfreported impulsivity and a questionnaire for the assessment of aggressive driving behavior, Aggressive Driving Behavior Questionnaire (ADBQ, Mouloua et al., 2007).

\subsubsection{Demographic Questionnaire}

Demographic questionnaire is created with the aim to obtain the comprehensive picture about the most important sociodemographic indicators (gender, age), driving experience (length of a valid driving license, annual distance traveled and category of vehicle driven), as well as participation in traffic accidents (during the whole driving experience). Here they reported the number of accidents in which they participated as drivers. The survey form included multiple choice answers, where respondents had the possibility to opt for one of the four alternatives regarding the number of accidents that were given as the range of values (first alternative involved the absence of an accident, the second between 1-3 accidents, third from 4 to 7 accidents and fourth from 8 to 11 accidents). The Table 1 shows a percentage distribution of the number of accidents per age categories.

Table 1

Percentage Distribution of the Number of Accidents per Age Categories

\begin{tabular}{|l|c|c|c|c|c|c|c|}
\hline \multirow{2}{*}{ No. of accidents } & \multicolumn{9}{|c|}{ Age } & Total [\%] \\
\cline { 2 - 8 } & $18-25$ & $26-35$ & $36-45$ & $46-55$ & $56-65$ & Over 65 & \\
\hline None & 3.3 & 15.4 & 17.0 & 6.2 & 2.0 & 0.3 & 44.3 \\
\hline $1-3$ & 4.3 & 3.9 & 19.7 & 14.1 & 2.6 & 0.3 & 44.9 \\
\hline $4-7$ & 1.0 & 0.0 & 3.3 & 3.6 & 1.0 & 0.0 & 8.9 \\
\hline $8-11$ & 0.0 & 0.0 & 0.3 & 0.3 & 1.3 & 0.0 & 2.0 \\
\hline Total [\%] & 8.5 & 19.3 & 40.3 & 24.3 & 6.9 & 0.7 & 100.0 \\
\hline
\end{tabular}

The respondents should also report the consequences of accidents (financial, injuries, mental trauma, etc.) expecting to offer the data about each accident a particular examinee had experienced. These data are not used in the analysis for two reasons. First, in the case of more than one experienced accident, aggregated data for these drivers is significantly complicate to present since there would be a large number of different groups. Statistical review of such results would not have much sense. On the other hand, a significant number of respondents did not accurately answered these questions for each of the consequences of past accidents, therefore the obtained data were largely unusable. 


\subsubsection{Barratt Impulsiveness Scale}

Barratt Impulsiveness Scale (BIS-11) is an instrument for impulsiveness assessment, authored by (Patton et al., 1995). This scale comprises 30 items, which include various relevant aspects of impulsive behavior and habits. The items were scored on a 4-point Likert scale $(1=$ rarely/ never, to $5=$ almost always/ always). It is important to emphasize that certain issues require the inversion of scores for answers when the question is phrased in the negative.

Use of Barratt Impulsiveness Scale as inventory for assessing personality/ behavior is recorded in the literature, during the period of over 50 years (BIS, Barratt, 1965), both for the purposes of scientific research and in clinical practice. BIS-11 is one of the most used inventories for assessing impulsiveness as a personality construct. Two-factor structure of the questions is extracted in three dimensions: Attention, Motor and Non-planning. One-factor structure generated the following correlates of impulsivity: Attention, Motor, Selfcontrol, Cognitive complexity, Perseverance, Cognitive instability.

\subsubsection{Aggressive Driving Behavior Questionnaire}

Aggressive Driving Behavior Questionnaire (ADBQ, Mouloua et al., 2007) is inventory that consists of 20 questions. At 6-points Likert scale of responses (from $1=$ never, to $6=$ almost always), respondents estimate the probability that a particular aggressive behavior will be manifested during driving.
According to factor analysis, conducted by (Gurda, 2012), questions are extracted in four subscales: Anger/aggression, Speeding and minor infractions, Over expression, and Judgment of other drivers. The higher total score of the responses indicates a higher level of aggressiveness of drivers.

\subsection{Statistical Analysis}

Data were analyzed using the Statistical Package for Social Scientists (SPSS) version 17. Descriptive statistics were used to present basic numerical results, such as means and standard deviations, as well as to display any observed differences in gender and age. Besides, the Spearman's correlation coefficients are analyzed between the instruments, the significance of differences between groups is determined using the Kruskal-Wallis test and hierarchical regression analysis is performed.

\section{Results}

The link between impulsiveness as personality trait (measured by BIS-11 scale) and aggressive driving (measured by ADBQ scale) was analyzed using Spearman's linear correlation coefficient (Table 2). As for the BIS-11 scale for measuring impulsiveness concerns, the values of correlation are shown, for both constructs that were generated in the three components using a two-factor structure (Attention, Motor and Non-planning) and constructs obtained from the one-factor structure (Attention, Motor, Self-control, Cognitive complexity, Perseverance, Cognitive instability). 
Table 2

Correlations Among Impulsiveness, and Aggressive Driving

\begin{tabular}{|c|c|c|c|c|c|c|c|c|c|c|c|c|c|c|c|}
\hline Variables & 1 & 2 & 3 & 4 & 5 & 6 & 7 & 8 & 9 & 10 & 11 & 12 & 13 & 14 & 15 \\
\hline \multicolumn{16}{|c|}{ BIS-11 Second-order subscales } \\
\hline 1.Attentional & - & & & & & & & & & & & & & & \\
\hline 2.Motor & $.262^{* *}$ & - & & & & & & & & & & & & & \\
\hline 3. Non-planning & .078 & $.326^{* *}$ & - & & & & & & & & & & & & \\
\hline \multicolumn{16}{|c|}{ BIS-11 First-order subscales } \\
\hline 4. Attention & $.797^{* *}$ & $.249^{* *}$ & .089 & - & & & & & & & & & & & \\
\hline $\begin{array}{l}\text { 5. Cognitive } \\
\text { Instability } \\
\end{array}$ & $.728^{* *}$ & $.173^{*}$ & .062 & $.198^{*}$ & - & & & & & & & & & & \\
\hline 6. Motor & $.201^{*}$ & $.899^{*}$ & $.261^{* *}$ & $.190^{*}$ & .131 & - & & & & & & & & & \\
\hline 7. Perservance & $.274^{* *}$ & $.607^{* *}$ & $.193^{*}$ & $.218^{*}$ & $.215^{*}$ & $.229^{* *}$ & - & & & & & & & & \\
\hline 8. Self-control & .040 & $.291^{* *}$ & $.917^{* *}$ & .018 & .046 & $.268^{* *}$ & .147 & - & & & & & & & \\
\hline $\begin{array}{l}\text { 9. Cognitive } \\
\text { Complexity }\end{array}$ & .041 & $.169^{*}$ & $.449^{* *}$ & .076 & .018 & .095 & $.176^{*}$ & .092 & - & & & & & & \\
\hline 10. Total score & $.569^{* *}$ & $.812^{* *}$ & $.654^{* *}$ & $.482^{* *}$ & $.410^{* *}$ & $.723^{* *}$ & $.523^{* *}$ & $.580^{* *}$ & & - & & & & & \\
\hline \multicolumn{16}{|l|}{$A D B Q$} \\
\hline $\begin{array}{l}\text { 11. Anger/ } \\
\text { aggression }\end{array}$ & .092 & $202^{*}$ & $.338^{* *}$ & .069 & .151 & $.255^{* *}$ & .040 & $.285^{* *}$ & .130 & $.300^{* *}$ & 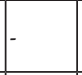 & & & & \\
\hline 12. Speeding & .119 & $.239^{* *}$ & $.333^{* *}$ & .138 & .093 & $.260^{* *}$ & .075 & $.308^{* *}$ & .115 & $.341^{* *}$ & $.768^{* *}$ & - & & & \\
\hline $\begin{array}{l}\text { 13. Overt } \\
\text { Expression }\end{array}$ & .099 & $.202^{*}$ & $.259^{* *}$ & .090 & .075 & $.319^{* *}$ & .088 & $.260^{* *}$ & .041 & $.319^{* *}$ & $.389^{* *}$ & $.491^{* *}$ & - & & \\
\hline $\begin{array}{l}\text { 14. Judgment } \\
\text { of other }\end{array}$ & $.249^{* *}$ & .159 & $.170^{*}$ & $.254^{* *}$ & $.176^{*}$ & $.170^{*}$ & .050 & .169 & .054 & $.270^{* *}$ & $.458^{* *}$ & $.419^{* *}$ & $.369^{* *}$ & - & \\
\hline 15. Total score & $.198^{*}$ & $.271^{* *}$ & $.380^{* *}$ & $.194^{*}$ & .161 & $.398^{* *}$ & .075 & $.322^{* *}$ & .091 & $.398^{* *}$ & $.836^{* *}$ & $.869^{* *}$ & $.686^{* *}$ & $.729^{* *}$ & \\
\hline
\end{tabular}

--Note: ADBQ (Aggressive Driving Behaviour Questionnaire)

${ }^{*} p<.05$.

${ }^{* *} p<.01$.

Looking at the dimensions of the twofactor analysis of the BIS-11 questionnaire, Attention correlated with Judgment of other ( $\mathrm{rs}=.249, \mathrm{p}<.01)$, as well as with an overall score of aggression $(\mathrm{rs}=.198, \mathrm{p}$ $<.05)$. As for the Motor dimension, a series of statistically significant correlations were obtained with the factors of ADBQ questionnaire: the Anger/aggression ( $\mathrm{rs}=$ .202 , $\mathrm{p}<.01)$, Speeding ( $\mathrm{rs}=.239, \mathrm{p}<.01)$, Overt Expression ( $\mathrm{rs}=.202, \mathrm{p}<.05)$ as with ADBQ Total score $(\mathrm{rs}=.271, \mathrm{p}<.01)$.
It is interesting to note that for the Nonplanning dimension, significant correlations with all forms of aggression are found. Higher positive correlations are obtained with the Total score of aggression ( $\mathrm{rs}=.380$, $\mathrm{p}<.01$ ), and then with Anger / aggression dimension ( $\mathrm{rs}=.338, \mathrm{p}<.01)$, Speeding dimension ( $\mathrm{rs}=.333, \mathrm{p}<.01$ ), with Overt Expression ( $\mathrm{rs}=.259, \mathrm{p}<.01)$, while the weakest positive linear relationship was found for the Judgment of other ( $\mathrm{rs}=.170$, $\mathrm{p}<.05)$. 
With respect to the factor structure, Attention dimensions was significantly positively related to the dimension Judgment of other $(\mathrm{rs}=.254, \mathrm{p}<.01)$, and with a Total score on aggression scale $(\mathrm{rs}=.194, \mathrm{p}<.05)$. Cognitive Instability subscale correlated with the Judgment of other ( $\mathrm{rs}=.176, \mathrm{p}$ $<.01)$. Motor impulsiveness was significantly positively related to all dimensions of aggressive behavior, as well as with the Total score for aggressiveness. The correlations of: Total score ADBQ (rs = .398, p <.01), with Overt Expression ( $r s=.319, \mathrm{p}<.01)$, with Speeding ( $\mathrm{rs}=.260, \mathrm{p}<.01)$, with Anger/ aggression ( $\mathrm{rs}=.255, \mathrm{p}<.01$ ), as well as the weakest with the Judgment other ( $\mathrm{rs}=.170$, $\mathrm{p}<.05)$ are found. Perseverance as subscale shows no significant correlation with any of the dimensions of aggression, while the Selfcontrol correlates with the Total score ADBQ $(\mathrm{rs}=.322, \mathrm{p}<.01)$, Speeding $(\mathrm{rs}=.308, \mathrm{p}$ $<.01)$, Anger / aggression ( $\mathrm{rs}=.285, \mathrm{p}<.01)$ and Overt Expression ( $r s=.260, \mathrm{p}<.01)$.

As expected, Impulsiveness Total score correlated significantly and positively with all the factors of aggressive driving (Anger) aggression: $\mathrm{rs}=.300, \mathrm{p}<.01$, Speeding: $\mathrm{rs}=$ $.341, \mathrm{p}<.01$, Overt Expression: $\mathrm{rs}=.319, \mathrm{p}$ $<.01$, Judgment of other: $\mathrm{rs}=.270, \mathrm{p}<.01)$.

In line with initial expectations, moderate correlation is found between the Overall scores of impulsiveness and aggression (rs $=.398, \mathrm{p}<.01)$. These results show more pronounced association compared to the findings of (Dahlen et al., 2005), where the BIS-11 instrument brought into a connection with the questionnaire Driving Anger Scale (DAS, Deffenbacher et al., 1994).

For further analysis, it is important to emphasize that a statistically significant correlation between certain variables from demographic questionnaires was determined. The relation was identified between the variables age and driving experience, compared to the total number of experienced traffic accidents.

\subsection{Hierarchical Regression Analyses}

To test a relationship between traffic accidents (total number of accidents per driver), impulsiveness, and the different forms of aggression while driving, two hierarchical regression analyzes, controlling for the effect of age and driving experience, were conducted. As previously reported in (Čubranić-Dobrodolac et al., 2017), variables Age and Driving experience were controlled because they were found to be statistically significantly correlated with traffic accidents. In the first analysis, the dependent variable was traffic accidents occurrence during the whole driving experience. Age and driving experience were entered as independent variables in the first block, and the Total score of impulsiveness was entered in the second block. In the second analysis, the dependent variable was the same-traffic accidents. Age and driving experience were entered as independent variables in the first block, and the Total score of aggressiveness in the second block. The main aim of these analyzes was to determine the predictive value of the impulsiveness and aggression of involvement in traffic crashes, controlling for age and driving experience.

In the first regression analysis, the variables for age and driving experience were entered in the first step and explained $17.4 \%$ of the variance of traffic accidents $(F(2,302)=$ $31.729, \mathrm{p}<.001)$. After the introduction of impulsiveness in the second step, the model explained $38.3 \%$ of the total variance ( $F$ $(3,301)=62.192, \mathrm{p}<.005)$. Impulsiveness 
through the overall obtained score explains the additional 20.9 percent of variance of experienced traffic accidents, even when the effect of age and driving experience is statistically removed $(\mathrm{F}(1,301)=101.192$, $\mathrm{p}<.001$. Further relationship is described by performing a t-test and by the following coefficients: $\beta=0.477, t=10.095, p<.001$. Since the $\mathrm{p}$ value is lower than 0.05 , this means the beta coefficient is statistically significant.

In the second hierarchical regression analysis, the variables for age and driving experience were introduced in the first step and explained, as in the first model, $17.4 \%$ of the variance in the occurrence of traffic accidents $(F(2,302)=31.729, \mathrm{p}<.001)$. After the introduction of the aggressiveness Total score in the second stage, the model explained $36 \%$ of the total variance $(\mathrm{F}(3,301)=56.320$, $\mathrm{p}<.001)$. Aggressiveness, seen through the Total score on the questionnaire, explained the additional $18.6 \%$ of the variance for traffic accidents involvement $(\mathrm{F}(3,301)=87.355$, $\mathrm{p}<.001)$. In addition to the variables of age and experience, aggressiveness accounts for a significant amount of the variance too $(\beta=$ $.439, \mathrm{t}=9.346, \mathrm{p}<.001)$.
The demographic variables age and driving experience, in line with preliminary expectations, explained a significant portion of the variance in the occurrence of traffic accidents. However, even when the impact of these demographic variables is removed, the total impulsiveness score did account for a significant amount of the variance in the total number of experienced accidents. This is also valid for the second model where after removing the impact of the variables age and driving experience, driver aggression as a trait still explains a large proportion of the total variance of traffic accidents, even higher than impulsiveness.

\subsection{Additional Results}

One of the research objectives in the study which require to be answered is if there are differences in the levels of impulsiveness and aggression in the total sample and among different groups of drivers (bus drivers, truck drivers and non-professional drivers). The results of descriptive statistics (the means and standard deviation) for BIS-11 and $A D B Q$ indicate the intensity of expression of observed behaviors and can be seen in Table 3.

\section{Table 3}

Descriptive Statistics for the BIS-11 and ADBQ by Driver Categories

\begin{tabular}{|l|c|c|}
\hline \multicolumn{1}{|c|}{ Variables } & Impulsiveness & Aggressiveness \\
\hline Bus drivers & $71.6(5.8)$ & $44.7(8.5)$ \\
\hline Truck drivers & $71(6.0)$ & $49.8(9.5)$ \\
\hline Non-professional drivers & $67.5(5.2)$ & $52.5(10.7)$ \\
\hline Total & $70.0(5.6)$ & $49(9.5)$ \\
\hline
\end{tabular}

$N=305$ (100-bus driver, 102-truck driver, 103-non-professional driver)

By applying the Kruskal Wallis test for determining the significance of the differences between the three observed groups of drivers, there were found statistically significant differences between groups in terms of impulsiveness, while in the case of aggressiveness there were no statistically significant differences (Table 4). 
Table 4

Differences Between Groups - Kruskal Wallis Test

\begin{tabular}{|c|c|c|}
\hline & Impulsiveness & Aggressiveness \\
\hline Chi-Square & 12.957 & .302 \\
\hline df & 2 & 2 \\
\hline Asymp. Sig. & .002 & .860 \\
\hline
\end{tabular}

Evidences from numerous studies conducted in different social and cultural environments have demonstrated impulsiveness to be a construct relevant to explaining both normal individual differences in personality and more extreme personality pathology among clinical populations, but there is no consensus on which score manifest high and low impulsivity scores. Some researchers accepted a score of 74 as the limit for increased impulsiveness according to the suggestions of (Patton et al., 1995). Some authors have indicated that respondents with this and higher score, exhibit a higher level of aggressiveness in behavior (Stanford et al., 2009). (Stanford et al., 2009) have offered an overview of research using BIS-11, suggesting the limit should be lowered to 72 , and that from this level an individual could be qualified as an impulsive person. A score between 52 and 71 represents the normal level of impulsiveness.

When it comes to overall score as an indicator of aggressiveness on ADBQ questionnaire, there are no clear guidelines for the score level which could be regarded as indicative in terms of increased aggressiveness in driving. The application of this questionnaire by its creator (Mouloua et al., 2007) on a sample of students indicated the value of average score is about 51.0. Further implementation of the ADBQ questionnaire by (Gurda, 2012), gave a slightly higher average scores for aggressive driving among students (55.2). Previous investigation suggested the questionnaire is a valid predictor of aggressive driving in a simulated environment (Brill et al., 2009).
Based on the descriptive indicators, the highest level of impulsiveness in the sample is recorded among bus driver (71.6) and truck drivers (71). Non-professional drivers showed the lowest score of impulsiveness. The mean score for the overall sample indicates a normal level of impulsiveness (in the whole sample of drivers). Bus drivers show elevated impulsivity scores which at the upper limit of the normal values proposed by (Stanford et al., 2009). Although the obtained scores are within the normal range, higher values were also found to be correlated with risky behaviors and also, recorded within clinical populations. For example, (Warren and South, 2006) carried out a research on female offenders (and found the score of 71.2 ), or in (Jallade et al., 2005) study on a sample of suicide attempters (71.6). (Fox, 2012) conducted the research with the sample consisted of student drivers in USA and impulsivity was measured by using the BIS-11 instrument. The average value of impulsiveness score was 66.2. (Pasa et al., 2013) examined two groups of drivers: in the first were drivers deprived of permits and in the second drivers without any traffic offense in the last 12 months. For offenders the obtained average impulsiveness score was 59.7, and for drivers with no violations 52 . (Gordon, 2007) registered the highest scores of 67.3 among different groups of driver adolescents in New Zealand. However, the different samples characteristics and statistical approaches used, could lead this kind of comparisons to be characterized as disputable. 
Considering the expression of aggression among different categories of drivers, higher levels of aggressiveness were found within non-professional drivers (52.5), while the scores for truck drivers are lower. The bus drivers, contrary to the previous instrument, show the lowest scores related to aggressiveness. However, the average recorded levels of aggression in all three categories of drivers, as well as for the sample in general, do not indicate a significantly high levels of aggressive driving, compared to previous studies (Mouloua et al., 2007; Gurda 2012). Moreover, on the contrary they are proven to be lower compared to the results of the above studies.

\section{Discussion}

Since impulsivity has often been related to aggressive behavior, due to the fact the inhibition deficits related to impulsivity can lead to behind the wheel aggressive behavior, besides other research questions, this study aims to analyze their relationship. In addition, the attempt was made to examine whether some of the indicators of road safety (primarily refers to the tendency towards experiencing traffic accidents) can be predicted on the basis of psychological constructs such as impulsiveness and aggressiveness in driving.

The study came up with some interesting results which should be further discussed. Firstly, BIS-11 and ADBQ scores are consistent to the values obtained from the other studies using the same research instruments. Then, in line with the initial expectations, a statistically significant correlation between the two questionnaires which measure similar phenomena in behavior was demonstrated, both for the total scores, as well as for the single dimensions covered by the questionnaire. Based on these results we can conclude that there is a similarity between the behavioral correlates of general impulsiveness and aggressive expression while driving. These results are in accordance with the results obtained in earlier studies that have addressed the same issue (Stanford and Barratt, 1992; Deffenbacher et al., 2000; 2003, Dahlen et al., 2005). On the other hand, demographic variables of age and driving experience, also, not unexpectedly, showed the correlation with the number of accidents that drivers had experienced.

Considering the recorded levels of impulsiveness between different groups of drivers, it is worth to note that the impulsiveness is mostly pronounced among bus drivers and truck drivers. Bus drivers show the scores which are at the upper limit of the normal values. These results can be interpreted in connection with increased stress exposure for this category of drivers. This group suffer from the effects of increased fatigue due to a prolonged working hours. Often, the rule on the time limit for total daily driving period of maximum 9 hours is neglected, and the situation is similar to the rules of necessary breaks while driving. On the other hand, one should not ignore the fact that truck drivers, as a category that obtained the similar level of impulsiveness compared to bus drivers, are usually alone in their journeys making them more vulnerable and pushing the tendency toward impulsive behavior. Similar values of the total scores were identified in several clinical trials among male offenders with personality disorders (Moeller et al., 2001; Rubio et al., 2007). However, looking at the average level of impulsiveness in the group of professional drivers in the present study, as well as for the others, supported by the 
findings from other studies we can conclude that it ranges within normal limits (Patton et al., 1995; Stanford et al., 2009).

In the results for ADBQ scale, somewhat different tendencies could be seen. The highest intensity of aggressive driving behavior is shown by non-professional drivers. These results can be interpreted in multiple ways. Not only the personality traits of anger/ hostility but also those of impulsiveness thus would be significantly related to aggression. But this does not necessarily mean a direct link among impulsiveness and aggression, as it has been shown by an investigation in a nonoffender sample of British males (McMurran et al., 2002). In line with the mentioned facts, it is possible that for professional drivers, control of aggressive manifestation in traffic is present to a greater extent due to the effects of experience and responsibility of their profession. On the other hand, as the statements in $\mathrm{ADBQ}$ questionnaire are related to specific driving situations in which the aggressive behavior is expressed, as opposed to the BIS-11 questionnaire that contains statements of general type, it is possible that professional drivers were more cautious in answering, their responses have largely been based on socially desirable forms of behavior.

The results of hierarchical regression analyzes show that high scores on scale of impulsiveness BIS-11, and the scale of aggressive driving behavior ADBQ formed less safe driving style expressed through a greater likelihood of experiencing accidents. Additional modules of such driving behavior are: the tendency toward behavioral risk taking, competitive behavior, satisfying current impulses and inability to think about the consequences of their own actions. Both scales explain the similar proportion of variance in the occurrence of accidents, even when the demographic variables, age and driving experience are excluded. These results are especially contrary to some studies in which the BIS-11 questionnaire was used as a predictor of traffic accidents (Jakubczyk et al., 2013; Xu et al., 2014).

Despite the attempt to conduct methodologically accurate research, this study has certain limitations. This type of survey did not allow the equal representation of both genders. The reason lies in the fact that all professional drivers in the observed companies are males. This limits the ability to generalize the results to the entire population of drivers.

Furthermore, the study results are based on data obtained from the self-reports. Such a method of collecting data can lead to distortions in the data because of socially desirable responding. Although the respondents were provided anonymity in testing, as well as guaranteed confidentiality, it is assumed that the drivers had some kind of delay in answering on certain aspects of behavior. This is especially likely when it comes to professional drivers, and among this population we can always count on a greater presence of socially desirable answers. Also, respondents were asked for any accident in which they had taken any active part as drivers, i.e. the question did not apply only to those accidents for which they were directly responsible. This is for several reasons. First, a survey research is generally characterized by the presence of some level of subjectivity and socially desirable responding. Accordingly, it is not realistic to expect that drivers would provide accurate and objective answers if the question is related only to accidents where they are considered to be at-fault. This particularly applies to the professional 
drivers who are suspicious about these types of studies, although it was emphasized that the survey has an anonymous character. On the other hand, it was not possible for authors to get the official data on accidents which the participants have caused. Further investigation would be welcome to minimize or eliminate some of these limitations. As a future research direction, it would be interesting to examine the impact of the considered variables on the near-miss accidents. A possible methodology could be the one proposed by (Girotto et al., 2016).

In conclusion, future investigators should compare $\mathrm{ADBQ}$ and BIS-11 data in relation to the different environmental and psychological factors to help researchers in understanding the complexity of this driving phenomenon. It would be useful to test this model introducing attitudes towards risky driving, especially sensation seeking as a phenomenon that is increasingly discussed in the scientific literature from the field of traffic safety (Zuckerman, 1994.; Jonah et al., 2001). Also, the use of multiple predictors in the analysis of traffic accidents and unsafe behaviors is recommended.

Having in mind the fact that traffic accidents are relatively rare events, it can be concluded that it is difficult to determine the predictive ability of the personality traits, as well as certain forms of behavior in their creation. Yet despite this, the findings suggest an important role of certain personal characteristics in unsafe behaviors in traffic. These knowledge could be used for different purposes.

When it comes to the policy implications, first it should be noticed that by using the proposed or similar assessment instruments with a satisfactory predictive power of traffic accidents occurrence, the criterion for selection of professional drivers of all categories could be improved. Besides, the recommendation is to introduce impulsiveness and aggressiveness measurement, as important determinants of driver behavior, in the process of testing the professional drivers who experienced traffic accidents. Further, the results of this research may find their implementation in the design of programs for the prevention of accidents and violation of the traffic laws, driver rehabilitation programs and promotion of safer driving styles, according to the personality characteristics of the driver. This is particularly important when the training programs for novice drivers are formed, since the beginning driving experience significantly direct drivers to adequate form of control of impulses and aggressive driving behavior (Özkan et al., 2010). This is the reason why it is important to measure and analyze impulsiveness and aggressiveness of all categories of drivers and implement programs to reduce impulsiveness and aggressiveness while driving. Accordingly, additional research on methods to reduce impulsiveness and aggressiveness of drivers would be useful.

\section{Acknowledgement}

This research was supported by the Serbian Ministry of Education, Science and Technological Development, project no. TR36022.

\section{References}

AAA Foundation for Traffic Safety. 2009. Aggressive Driving Research Update. Available from internet: <http://www.aaafoundation.org/pdf/ AggressiveDrivingResearchUpdate2009>.

Anderson, C.A.; Bushman, B.J. 2002. Human Aggression, Annual Review of Psychology 53: 27-51. Available from internet: <http://dx.doi.org/10.1146/ annurev.psych.53.100901.135231 2 . 
Arthur J.W.; Bell, S.T.; Edwards, B.D.; Day, E.A.; Tubré, T.C.; Tubré, A.H. 2005. Convergence of selfreport and archival crash involvement data: A twoyear longitudinal follow up, Human Factors 47(2): 303-313. Available from internet: <http://dx.doi. org/10.1518/0018720054679416>.

Barratt ES. 1965. Factor analysis of some psychometric measures of impulsiveness and anxiety, Psychological Reports 16(2): 547-554. http://dx.doi.org/10.2466/ pr0.1965.16.2.547

Barratt, E.S.; Slaughter, L. 1998. Defining, measuring, and predicting impulsive aggression: A heuristic model, Behavior Science Law 16(3): 285-302. Available from internet: <http://dx.doi.org/10.1002/ (SICI)1099-0798(199822)16:3\%3C285::AID BSL308\%3E3.0.CO;2-4>.

Baron, R.A.; Richardson, D.R. 1994. Human Aggression: Naturalistic Approaches. Routledge, London, Great Britain, 25-41.

Benfield, J.A.; Szlemko, W.J.; Bell, P.A. 2007. Driver personality and anthropomorphic attributions of vehicle personality relate to reported aggressive driving tendencies, Personality and Individual Differences 42(2): 247-258. Available from internet: <https://doi. org/10.1016/j.paid.2006.06.016>.

Bone, S. A.; Mowen, J.C. 2006. Identifying the traits of aggressive and distracted drivers: A hierarchical trait model approach, Journal of Consumer Behaviour 5(5): 454-464. Available from internet: <http://dx.doi. org/10.1002/cb.193>.

Brill, J. C.; Mouloua, M.; Shirkey, E. 2009. Predictive validity of the Aggressive Driver Behavior Questionnaire (ADBQ) in a simulated environment. In Proceedings of the 53rd Annual Meeting of the Human Factors and Ergonomics Society, 1334-1337.
Buss, A.H.; Perry, M. 1992. The aggression questionnaire, Journal of Personality and Social Psychology 63(3): 452-459. Available from internet: <http://dx.doi. org/10.1037/0022-3514.63.3.452>.

Clarke, D.D.; Ward, P.; Bartle, C.; Truman, W. 2006. Young driver accidents in the UK: the influence of age, experience: and time of day, Accident Analysis and Prevention 38(5): 871-878. Available from internet: <http://dx.doi.org/10.1016/j.aap.2006.02.013>.

Critchfield, K.L.; Levy, K.N.; Clarkin, J.F. 2004. The relationship between impulsivity, aggression, and impulsive-aggression in borderline personality disorder: An empirical analysis of self-report measures, Journal of Personality Disorders 18(6): 555-570. Available from internet: <http://dx.doi.org/10.1521/ pedi.18.6.555.54795>.

Cyders, M. A.; Smith, G.T.; Spillane, N.S.; Fischer, S.; Annus, A.M., Peterson, C. 2007. Integration of impulsivity and positive mood to predict risky behavior: Development and validation of a measure of positive urgency, Psychological Assessment 19(1): 107-118. Available from internet: <http://dx.doi. org/10.1037/1040-3590.19.1.107>.

Čubranić-Dobrodolac, M.; Lipovac, K.; Čičević, S.; Antić, B. 2017. A model for traffic accidents prediction based on driver personality traits assessment, Promet - Traffic \& Transportation 29(6): 631-642. Available from internet: <https://doi. org/10.7307/ptt.v29i6.2495>.

Dahlen, E.R.; Martin, R.C.; Ragan, K.; Kuhlman, M.M. 2005. Driving anger, sensation seeking, impulsiveness, and boredom proneness in the prediction of unsafe driving, Accident Analysis and Prevention 37(2): 341-348. Available from internet: <http://dx.doi.org/10.1016/j. aap.2004.10.006>. 
Dahlen, E.R.; Edwards, B.D.; Tubré, T.; Zyphur, M.J.; Warren, C.R. 2012. Taking a look behind the wheel: An investigation into the personality predictors of aggressive driving, Accident Analysis and Prevention 45(2): 1-9. Available from internet: <http://dx.doi. org/10.1016/j.aap.2011.11.012>.

Deffenbacher, J.L.; Oetting, E.R.; Lynch, R.S. 1994. Development of a driving anger scale, Psychological Reports 74(1): 83-91. Available from internet: <http://dx.doi. org/10.2466/pr0.1994.74.1.83>.

Deffenbacher, J.L.; Huff, M.E.; Lynch, R.S.; Oetting, E.R.; Salvatore, N.F. 2000. Characteristics and treatment of high-anger drivers, Journal of Counseling Psychology 47(1): 5-17. Available from internet: <http:// dx.doi.org/10.1037/0022-0167.47.1.5>.

Deffenbacher, J.L.; Lynch, R.S.; Oetting, E.R.; Swaim, R.C. 2002. The Driving Anger Expression Inventory: A measure of how people express their anger on the road, Behaviour Research and Therapy 40(6): 717-737. Available from internet: <http://dx.doi.org/10.1016/ S0005-7967(01)00063-8>.

Deffenbacher, J.L.; Filetti, L.B.; Richards, T.L.; Lynch, R.S.; Oetting, E.R. 2003. Characteristics of two groups of angry drivers, Journal of Counseling Psychology 50(2): 123-132. Available from internet: <http://dx.doi. org/10.1037/0022-0167.50.2.123>.

De Oña, J.; Lopez, G.; Mujalli, R.; Calvo, F.J. 2013. Analysis of traffic accidents on rural highways using latent class clustering and Bayesian networks, Accident Analysis and Prevention 51: 1-10. Available from internet: <https://doi.org/10.1016/j.aap.2012.10.016>.

Eiksund, S. 2009. A geographical perspective on driving attitudes and behavior among young adults in urban and rural Norway, Safety Science 47(4): 529-536. Available from internet: <http://dx.doi.org/10.1016/j. ssci.2008.07.034>.
Elander, J.; West, R.; French, D. 1993. Behavioural Correlates: Individual Differences in Road-Traffic Crash Risk: An Examination of Methods and Findings, Psychological Bulletin 113(2): 279 - 294. Available from internet: <http://dx.doi.org/10.1037/00332909.113.2.279>.

Evans, L. 1991. Traffic Safety and the Driver. Van Nostrand Reinhold, New York.

Eysenck, S.B.G.; Eysenck, H.J. 1978. Impulsiveness and venturesomeness: Their position in a dimensional system of personality description, Psychological Reports 43(3): 1247-1255. Available from internet: <http:// dx.doi.org/10.2466/pr0.1978.43.3f.1247>.

Ge, Y.; Zhang, Q.; Zhang, J.; Zhao, W.; Yu, T.; Zhang, K.; Qu, W. 2016. Validation of the Driver's Angry Thoughts Questionnaire (DATQ) in a Chinese sample, Accident Analysis and Prevention 95: 362-372. Available from internet: <http://dx.doi.org/10.1016/j.aap.2016.04.025>.

Girotto, E.; de Andrade, S.M.; González, A.D.; Mesas, A.E. 2016. Professional experience and traffic accidents/ near-miss accidents among truck drivers, Accident Analysis and Prevention 95: 299-304. Available from internet: <http://dx.doi.org/10.1016/j.aap.2016.07.004>.

Gordon, M.A. 2007. Evaluating the Balloon Analogue Risk Task (BART) as a Predictor of Risk Taking in Adolescent and Adult Male Drivers. Thesis, Master of Social Sciences (MSocSc). The University of Waikato, Hamilton, New Zealand. Available from internet: <http://hdl.handle.net/10289/2455>.

Gurda, A. 2012. Evaluating the Psychometric Properties of the Aggressive Driving Behavior Questionnaire $(A D B Q)$. A thesis submitted in partial fulfillment of the requirements for the Honors in the Major Program in Psychology, University of Central Florida, Orlando, Florida. Available from internet: <http://stars.library.ucf.edu/cgi/viewcontent. cgi ?article $=2271 \&$ context $=$ honorstheses1990-2015 $>$. 
Fernandes, R.; Job, R.F.S.; Hatfield, J. 2007. A challenge to the assumed generalizability of prediction and countermeasure for risky driving: Different factors predict different risky driving behaviors, Journal of Safety Research 38(1): 59-70. Available from internet: <http://dx.doi.org/10.1016/j. jsr.2006.09.003>.

Fox, R.T. 2012. Examining Attention, Impulsiveness, and Cognitive Failures in Driving Behaviors, Electronic Theses and Dissertations. Paper 1465. Available from internet: <http://dc.etsu.edu/etd/1465>.

Furnham A.; Saipe J. 1993. Personality Correlates of Convicted Drivers, Personality and Individual Differences 14(2): 329-336. Available from internet: <http://dx.doi. org/10.1016/0191-8869(93)90131-L>.

Hansen, C.P. 1988. Personality characteristics of the accident involved employee, Journal of Business and Psychology 2(4): 346-365. Available from internet: <http://dx.doi.org/10.1007/BF01013766>.

Harre, R.; Lamb, R. 1983. The encyclopedic dictionary of psychology. Basil Blackwell Publisher Limited, Great Britain.

Jakubczyk, A.; Klimkiewicz, A.; Wnorowska, A.; Mika, K.; Bugaj, M.; Podgórska, A.; Barry, K., Blow, F.C.; Brower, K.J.; Wojnar, M. 2013. Impulsivity, risky behaviors and accidents in alcohol-dependent patients, Accident Analysis and Prevention 51: 150-155. Available from internet: <http://dx.doi.org/10.1016/j. aap.2012.11.013>.

Jallade, C.; Sarfati, Y.; Hardy-Bayle, M.C. 2005. Clinical evolution after self-induced or accidental traumatism: A controlled study of the extent and the specificity of suicidal catharsis, Journal of Affective Disorders 85(3): 283-292. Available from internet: <http://dx.doi. org/10.1016/j.jad.2004.11.002>.
Jonah, B.A.; Thiessen, R.; Au-Yeung, E. 2001. Sensation seeking, risky driving and behavioural adaptation, Accident Analysis and Prevention 33(5): 679-684. Available from internet: <http://dx.doi.org/10.1016/S00014575(00)00085-3>.

Jovanovic, D.; Lipovac, K.; Stanojevic, P.; Stanojevic, D. 2011. The effects of personality traits on driving-related anger and aggressive behaviour in traffic among Serbian drivers, Transportation Research Part F: Traffic Psychology and Behaviour 14(1): 43-53. Available from internet: <http://dx.doi.org/10.1016/j.trf.2010.09.005>.

Kanaan, A.; Huertas, P.; Santiago, A.; Sánchez, J.A.; Martínez, P. 2009. Incidence of different health factors and their influence on traffic accidents in the province of Madrid, Spain, Legal Medicine 11(Supplement 1): S333-S336. Available from internet: <http://dx.doi. org/10.1016/j.legalmed.2009.01.010>.

Koushki, P.A.; Bustan, M. 2006. Smoking, belt use, and road accidents of youth in Kuwait, Safety Science 44(8): 733-746. Available from internet: <http://dx.doi. org/10.1016/j.ssci.2006.03.003>.

Krahé, B.; Fenske, I. 2002. Predicting aggressive driving behavior: the role of macho personality, age, and power of car, Aggressive Behavior 28(1): 21-29. Available from internet: <http://dx.doi.org/10.1002/ab.90003>.

McMurran, M.; Blair, M.; Egan, V. 2002. An investigation of the correlations between aggressiveness, impulsiveness, social problem-solving, and alcohol use, Aggressive Behavior 28(6): 439-445. Available from internet: <http://dx.doi.org/10.1002/ab.80017>.

Miles, D.E.; Johnson, G.L. 2003. Aggressive driving behaviors: are there psychological and attitudinal predictors? Transportation Research Part F: Traffic Psychology and Behaviour 6(2): 147-161. Available from internet: <http://dx.doi.org/10.1016/S1369-8478(03)00022-6>. 
Moeller, G.; Barratt, E.; Dougherty, D.; Schmitz, J.; Swann, A. 2001. Psychiatric aspects of impulsivity, American Journal of Psychiatry 158(11): 1783-1793. Available from internet: <http://dx.doi.org/10.1176/ appi.ajp.158.11.1783>.

Mouloua, M.; Brill, J. C.; Shirkey, E. 2007. Gender differences and aggressive driving behavior: A factor analytic study. In Proceedings of the 51st Annual Meeting of the Human Factors and Ergonomics Society, Baltimore, MD, 1283-1286.

Özkan, T.; Lajunen, T.; Parker, D.; Sümer, N.; Summala, H. 2010. Symmetric relationship between self and others in aggressive driving across gender and countries, Traffic Injury Prevention 11(3): 228-239. Available from internet: <http://dx.doi.org/10.1080/15389581003788864>.

Parker, D.; Lajunen, T.; Stradling, S. 1998. Attitudinal predictors of interpersonally aggressive violations on the road, Transportation Research Part F: Traffic Psychology and Behaviour 1(1): 11-24. Available from internet: <http:// dx.doi.org/10.1016/S1369-8478(98)00002-3>.

Pasa, G. G.; Sousa, T.; Guimarães, L.; Pechansky, F. 2013. Risk behavior, sensation seeking and impulsivity: study comparing drunk drivers with sober drivers. In Proceedings of $20^{\text {th }}$ International Conference on Alcohol, Drugs and Traffic Safety, Brisbane, Queensland, Australia, 1-6. Available from internet: <http://www.icadtsinternational.com/ files/documents/2013_102.pdf $>$.

Patton, J.H.; Stanford, M.S.; Barratt, E.S. 1995. Factor structure of the Barratt Impulsiveness Scale, Journal of Clinical Psychology 51(6): $768-$ 774. Available from internet: <http://dx.doi. org/10.1002/1097-4679(199511)51:6\%3C768::AIDJCLP2270510607\%3E3.0.CO;2-1>.

Plutchik, R.; van Praag, H.M. 1995. The nature of impulsivity: definitions, ontology, genetics, and relations to aggression. In E. Hollander and D. J. Stein (Eds.), Impulsivity and Aggression, 7-24. Wiley, New York.
Renner, W.; Anderle, F.G. 2000. Venturesomeness and extraversion as correlates of juvenile drivers' traffic violations, Accident Analysis and Prevention 32(5): 673-678. Available from internet: <http://dx.doi.org/10.1016/ S0001-4575(99)00103-7>.

Roads of Serbia. 2016. Annual Average Daily Traffic in 2015. Available from internet: <http://www.putevisrbije.rs/images/pdf/brojanje/2015/tabela_saobracajnog_ opterecenja_na_dp_IAreda_preliminarni_rezultati.pdf $>$.

Road Traffic Safety Agency, Republic of Serbia. 2015. Internal document of the Agency. Belgrade: Road Traffic Safety Agency.

Rubio, G.; Jimenez, M.; Rodriguex-Jimenez, R.; Martinez, I.; Iribarren, M.M.; Jimenez-Arriero, M.A.; Ponce, G.; Ávila, C. 2007. Varieties of impulsivity in males with alcohol dependence. The role of cluster-B personality disorder, Alcoholism: Clinical and Experimental Research 31(11): 1826-1832. Available from internet: <http://dx.doi.org/10.1111/j.1530-0277.2007.00506. $\mathrm{x}>$.

Sârbescu, P.; Stanojevic, P.; Jovanovic, D. 2014. A cross-cultural analysis of aggressive driving: Evidence from Serbia and Romania, Transportation Research Part F: Traffic Psychology and Behaviour 24: 210-217. Available from internet: $<$ http://dx.doi.org/10.1016/j. trf.2014.04.002>.

Scott-Parker, B.; Watson, B.; King, M.J. 2009. Understanding the psychosocial factors influencing the risky behavior of young drivers, Transportation Research Part F: Traffic Psychology and Behaviour 12(6): 470-482. Available from internet: <http://dx.doi.org/10.1016/j. trf.2009.08.003>.

Stanford, M.S.; Barratt, E.S. 1992. Impulsivity and the multi-impulsive personality disorder, Personality and Individual Differences Journal 13(7): 831-834. Available from internet: <http://dx.doi.org/10.1016/01918869(92)90057-V>. 
Stanford, M.S.; Greve, K.W.; Boudreanx, J.K.; Mathias, C.W.; Brumbelow, J.L. 1996. Impulsiveness and risktaking behavior: comparison of high-school and college students using the Barratt impulsiveness Scale, Personality and Individual Differences 21(6): 1075-1973. Available from internet: <http://dx.doi.org/10.1016/S01918869(96)00151-1>.

Stanford, M.S.; Mathias, C.W.; Dougherty, D.M.; Lake, S.L.; Anderson, N.E.; Patton, J.H. 2009. Fifty years of the Barratt Impulsiveness Scale: An update and review, Personality and Individual Differences 47(5): 385-395. Available from internet: <http://dx.doi.org/10.1016/j. paid.2009.04.008>.

Tasca, L. (2000). A review of the literature on aggressive driving research. Ontario, Canada: Ontario Advisory Group on Safe Driving Secretariat, Road User Safety Branch, Ontario Ministry of Transportation. 25 p.

Ulleberg, P.; Rundmo T. 2003. Personality, Attitudes and Risk Perception as Predictors of Risky Driving Behaviour among Young Drivers, Safety Science 41(5): 427-443. Available from internet: <http://dx.doi. org/10.1016/S0925-7535(01)00077-7>.
Warren, J. I.; South, S. C. 2006. Comparing the constructs of antisocial personality disorder and psychopathy in a sample of incarcerated women, Behavioral Sciences \& the Law 24: 1-20. Available from internet: <http://dx.doi.org/10.1002/bsl.663>.

Waylen, A.E.; McKenna, F.P. 2008. Risky attitudes towards road use in pre-drivers, Accident Analysis and Prevention 40(3): 905-911. Available from internet: <http://dx.doi.org/10.1016/j.aap.2007.10.005>.

World Health Organization (WHO). 2015. Road Traffic Injuries 2014. Available from internet: <http://apps.who. int/iris/bitstream/10665/112738/1/9789240692671 eng.pdf $>$.

Xu, J.; Li, J.; Jiang, L. 2014. The effects of situational factors and impulsiveness on drivers' intentions to violate traffic rules: Difference of driving experience, Accident Analysis and Prevention 62: 54-62. Available from internet: <http://dx.doi.org/10.1016/j.aap.2013.09.014>.

Zuckerman, M. 1994. Behavioural Expressions and Biosocial Bases of Sensation Seeking. University of Cambridge Press, Cambridge. 